\title{
Collagen synthesis and collagenase activity of cryopreserved heart valves
}

Masashi Kano, MDa

Yutaka Masuda, MD, PhD

Takashi Tominaga, MD

Takaki Hori, MD, PhDa

Takashi Kitaichi, MDa

Masanori Yoshizumi, MD, $\mathrm{PhD}^{\mathrm{b}}$

Tetsuya Kitagawa, MD, $\mathrm{PhD}^{\mathrm{a}}$
From the Departments of Cardiovascular Surgery ${ }^{\mathrm{a}}$ and Pharmacology, ${ }^{\mathrm{b}}$ The University of Tokushima School of Medicine, Tokushima, Japan.

Received for publication Sept 7, 2000; revisions requested Feb 27, 2001; accepted for publication Feb 27, 2001.

Address for reprints: Yutaka Masuda, MD, $\mathrm{PhD}$, Department of Cardiovascular Surgery, The University of Tokushima School of Medicine, 2-50-1 Kuramoto, Tokushima 770-8503, Japan.

J Thorac Cardiovasc Surg 2001;122:706-11

Copyright () 2001 by The American Association for Thoracic Surgery

0022-5223/2001 \$35.00+ $0 \quad \mathbf{1 2 / 1 / 1 1 5 4 2 1}$

doi: $10.1067 / \mathrm{mtc} .2001 .115421$
Objective: Durability of the valve seems to be dependent on the remodeling ability of the valve itself, which is controlled by both collagen synthesis and collagenolytic activity of valvular fibroblasts and endothelial cells. However, the balance of collagen synthesis and collagenolysis of the cryopreserved valve has not yet been clearly revealed. Thus, we assessed the collagen synthesis and collagenolysis ability of the cryopreserved valve.

Methods: Twelve valves were divided into 2 groups: freshly harvested valves ( $\mathrm{n}=$ $6)$ and cryopreserved valves $(n=6)$. We measured the collagen content using Sirius red, a dye selective to the collagen. Collagen synthesis was evaluated by means of the tritiated proline incorporation method. Noncollagenase-digestible counts, which represent protein synthesis, and collagenase-digestible counts, which represent collagen synthesis, were estimated. Collagenase activity of the valves was assessed by gelatin zymography.

Results: The collagen content of the cryopreserved group was maintained. The noncollagenase-digestible counts of the cryopreserved group decreased from $3862 \pm$ 1180 counts $/ \mathrm{mg}$ to $1174 \pm 1362$ counts $/ \mathrm{mg}$, and the collagenase-digestible counts of the cryopreserved group were $831 \pm 762$ counts $/ \mathrm{mg}$ compared with the value of $1062 \pm 136$ counts/mg for the freshly harvested group. The collagenase activity of the cryopreserved group was observed at the same level as that of the freshly harvested group, despite the serious endothelial damage of the cryopreserved valves.

Conclusions: Although the collagen synthesis of cryopreserved valves was relatively maintained, the protein synthesis was highly diminished, and the collagenolysis ability was activated immediately after the thawing process. These results imply that the cryopreservation procedure itself may cause the collagen metabolism to be on the degradable side, which will lead to valve failure.

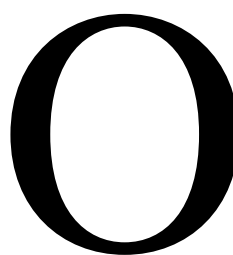

ver the past decade, several investigators, including us, have reported that loss of endothelial cells of cryopreserved valves may be inevitable, even with the current preservation techniques. Therefore, prolonged valve competence and durability of cryopreserved valves have been thought to be derived from the viability of the donor fibroblast, which can remodel the matrix assembly, ${ }^{1-3}$ or the quality of the original collagenous skeleton, which is the main component of the matrix assembly. There are some experimental studies that favor persistence of donor fibroblast viability after implantation..$^{4-7}$ On the other hand, some clinical studies do not favor donor fibroblast viability after implantation and insist on pre- 
serving the intact original collagen network, ${ }^{8-12}$ which provides the structural basis of the valve matrix, for the longterm performance of allograft valves. Controlled collagenolysis ability is thought to play an important role as the first step of the remodeling process, ${ }^{13}$ and consequent collagen synthesis is a second step. The present investigation was undertaken to examine the collagenolytic activity and collagen synthesis of cryopreserved valves.

\section{Materials and Methods \\ Collection and Processing of Cryopreserved Valves}

Twelve fresh porcine hearts were obtained from a local slaughterhouse immediately after the animals' deaths and immediately placed into the transport medium (cold Ringer's lactate solution). The pulmonary valves were dissected, and each cusp was excised in our laboratory within 1 hour after death. All cusps were divided into 2 groups: freshly harvested cusps $(n=6)$ and cryopreserved cusps $(n=6)$. The cryopreservation technique was that of Tominaga and associates. ${ }^{14}$ In brief, after antibiotic sterilizing treatment $(240 \mu \mathrm{g} / \mathrm{mL}$ cefazolin, $120 \mu \mathrm{g} / \mathrm{mL}$ lincomycin, 50 $\mu \mathrm{g} / \mathrm{mL}$ vancomycin, and $100 \mu \mathrm{g} / \mathrm{mL}$ polymyxin B) at $4^{\circ} \mathrm{C}$ for 24 hours, the cryopreserved specimens were transferred to TC199 culture medium with 5\% $\mathrm{N}$-2-hydroxyethylpiperazine- $\mathrm{N}$-2-ethanesulfonic acid buffer, $10 \%$ calf serum, and $10 \%$ dimethyl sulfoxide (Fisher Scientific Co, Pittsburgh, Pa) and were frozen with a programmable freezer (Cryomed model 1050; Forma Scientific Co, Marietta, Ohio) that lowered the temperature $1{ }^{\circ} \mathrm{C}$ per minute down to a temperature of $-80^{\circ} \mathrm{C}$. The specimens were immediately immersed in the vapor phase of a liquid nitrogen freezer $\left(-196^{\circ} \mathrm{C}\right)$. After a week of storage, the cryopreserved specimens were thawed immediately in a $40^{\circ} \mathrm{C}$ shaken water bath and then analyzed.

\section{Qualitative Analysis of Collagen Fiber and Measurement of Collagen Contents}

Sirius red (Muto Pure Chemicals, Tokyo, Japan) is a dye selective to the collagen. ${ }^{15,16}$ First, we visualized the collagen fibers of a cryopreserved crude cusp with a confocal scanning microscope because some fixing and slicing procedures may be influenced on them. ${ }^{14}$ Next, we measured the collagen contents. In brief, the cusps were immersed in $2 \mathrm{~mL}$ of saturated picric acid containing $0.1 \%$ Sirius red in a $35-\mathrm{mm}$ culture dish. The dishes were gently shaken at room temperature for 30 minutes in the dark. After staining, the cusps were rinsed 5 times with distilled water until the fluid was colorless. The cusps were put into a tube with $1 \mathrm{~mL}$ of $0.1 \mathrm{~N} \mathrm{NaOH}$ in absolute methanol (1:1, vol/vol). Each tube was gently shaken for a minute with the vortex mixer, and all the dye was eluted from the cusps. The amount of eluted dye was measured in a spectrophotometer at $540 \mathrm{~nm}$ (ie, the wavelength corresponding to the maximal absorbency of Sirius red).

\section{Measurement of Collagen and Protein Synthesis}

The protein production, including collagen, was assessed by using the tritiated $\left({ }^{3} \mathrm{H}\right)$ proline $\left(\mathrm{L}-\left[2,{ }^{3}-{ }^{3} \mathrm{H}\right]\right.$ proline; Amersham International, Little Chalfont, United Kingdom) incorporation method. ${ }^{17,18}$ Total ${ }^{3} \mathrm{H}$-proline incorporation into a cusp for 24 hours was expressed as noncollagenase-digestible counts (NDCs), which represents the total protein synthesis of the cusp. ${ }^{3} \mathrm{H}$-proline
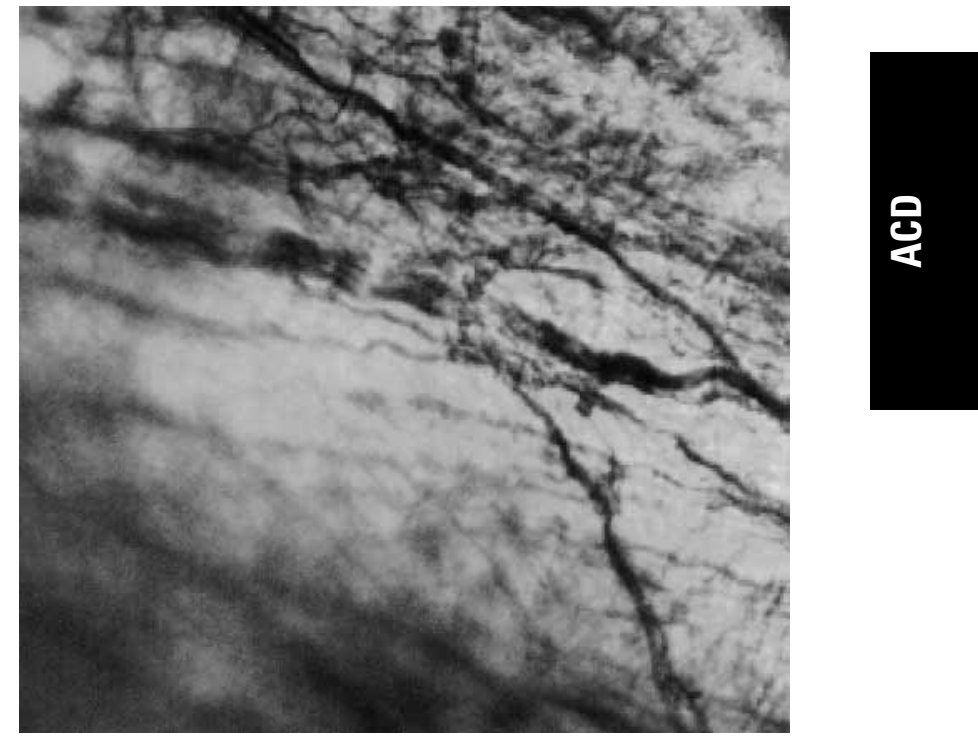

Figure 1. Photomicrograph of a cryopreserved porcine heart cusp with Sirius red dye. Collagen fibers are stained red. (Original magnification $200 \times$.)

incorporation into the collagenous proteins of a cusp was estimated as collagenase-digestible counts (CDCs), which represent the collagen synthesis of the cusp. Each cusp was cut into 2 pieces. One half of the cusp was used for NDC analysis, and the other half was used for CDC analysis.

In brief, after the cusps had been washed with phosphatebuffered saline solution, each half cusp was placed in a $35-\mathrm{mm}$ dish with $2 \mathrm{~mL}$ of minimum essential medium plus ascorbic acid $(50 \mu \mathrm{g} / \mathrm{mL})$ with $5 \%$ serum albumin. One and one-half hours later, the medium was replaced by $2 \mathrm{~mL}$ of the same medium plus $\beta$-amino-propionitrile $(50 \mu \mathrm{g} / \mathrm{mL})$ and $74 \mathrm{KBq} / \mathrm{mL}{ }^{3} \mathrm{H}$ proline, and the cusp was incubated for 24 hours. After this labeling period, $2 \mathrm{~mL}$ of $50 \mathrm{mmol} / \mathrm{L}$ Tris- $\mathrm{HCl}(\mathrm{pH} 7.6$ containing $0.25 \mathrm{~mol} / \mathrm{L}$ ethylenediamine tetraacetic acid), $0.1 \mathrm{~mol} / \mathrm{L} N$ ethylmaleimide, and $10 \mathrm{mmol} / \mathrm{L}$ phenylmethylsulfonyl fluoride was added to each dish, and the residual ${ }^{3} \mathrm{H}$-proline was removed. After being washed with $50 \mathrm{mmol} / \mathrm{L}$ Tris- $\mathrm{HCl}(\mathrm{pH} 7.6$ containing $1 \mathrm{mmol} / \mathrm{L}$ proline), each half cusp was cut into pieces with $1 \mathrm{~mL}$ of medium.

For the assay of NDCs, a 10\% trichloroacetic acid (TCA) solution was added to each dish to precipitate the protein, and the specimens were centrifuged ( $2000 \mathrm{rpm}$ ) for 5 minutes. The radioactive sediments were separated from free ${ }^{3} \mathrm{H}$-proline by means of repeated $(3 \times)$ washes with $5 \%$ TCA containing $1 \mathrm{mmol} / \mathrm{L}$ proline. The final sediments were suspended in $0.75 \mathrm{~mL}$ of $0.2 \mathrm{~mol} / \mathrm{L} \mathrm{NaOH}$ and neutralized by the addition of $0.3 \mathrm{~mL}$ of $1 \mathrm{~mol} / \mathrm{L} \mathrm{N}$-2-hydroxyethylpiperazine- $N$-2-ethanesulfonic acid buffer and $0.3 \mathrm{~mL}$ of 0.15 $\mathrm{mol} / \mathrm{L} \mathrm{HCl}$. The radioactivity of the suspensions from this solution was measured as NDCs.

For the evaluation of CDCs, $0.5 \mathrm{~mL}$ of $20 \mathrm{mmol} / \mathrm{L}$ Tris- $\mathrm{HCl}$ ( $\mathrm{pH} 7.6$ containing $50 \mathrm{mmol} / \mathrm{L} \mathrm{CaCl}_{2}$ ) and $0.2 \mathrm{~mL}$ of $24 \mathrm{IU}$ collagenase (Muto Pure Chemicals) was added to a ${ }^{3} \mathrm{H}$-proline-labeled half cusp, which was cut into pieces. The mixture was then incubated for 3 hours at $37^{\circ} \mathrm{C}$ for collagen digestion. The digestion was 


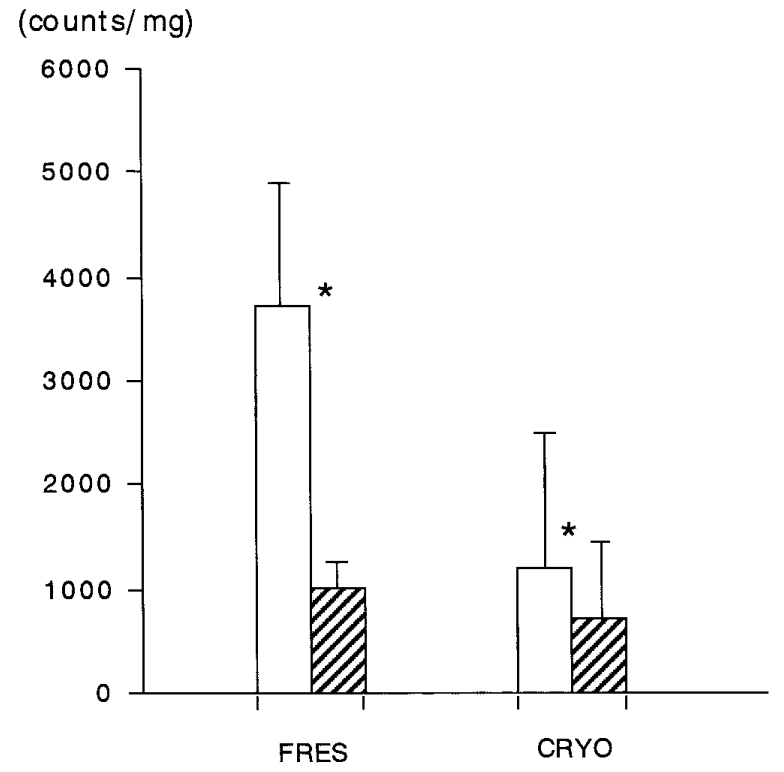

Figure 2. Collagen and protein synthesis of fresh (FRES) and cryopreserved (CRYO) cusps. Open columns show NDCs, and hatched columns show CDCs. Values are expressed as radioactive counts per milligram wet weight of cusp (means \pm SD). Values were significantly different $(P<.05)$ when compared with those of freshly harvested group.

terminated by the addition of TCA and tannic acid up to final concentrations of $0.3 \mathrm{mmol} / \mathrm{L}$ and $1.5 \mathrm{mmol} / \mathrm{L}$, respectively. After centrifugation (10 minutes at $3000 \mathrm{rpm})$, the supernatant was counted in a liquid scintillation counter. CDCs and NDCs were quantified per half cusp wet weights.

\section{Analysis of Collagenase Activity}

Collagenolytic activity was identified by gelatin substrate zymography, which was obtained by means of electrophoresis in the presence of sodium dodecylsulfate in polyacrylamide gel containing 1 $\mathrm{mg} / \mathrm{mL}$ gelatin (Sigma Chemical Co, St Louis, Mo). ${ }^{19-21}$ In brief, culture medium after 24 hours' incubation of a specimen without growth factors was used for this assay. A mixture of a $45-\mu \mathrm{L}$ sample and $15 \mu \mathrm{L}$ of conditioned buffer was loaded onto the gel. Molecular weight standard proteins (Bio-Rad, Hercules, Calif) were run simultaneously. After electrophoresis, the gel was washed twice with $2 \%$ Triton X100 for 1 hour to remove sodium dodecylsulfate with $10 \mathrm{mmol} / \mathrm{L}$ Tris- $\mathrm{HCl}(\mathrm{pH} 8.0)$ and subsequently incubated for 18 hours at $37^{\circ} \mathrm{C}$ in $50 \mathrm{mmol} / \mathrm{L}$ Tris- $\mathrm{HCl}(\mathrm{pH} 8.0)$ containing $10 \mathrm{mmol} / \mathrm{L} \mathrm{CaCl}_{2}$ and $1 \mu \mathrm{mol} / \mathrm{L} \mathrm{ZnCl}_{2}$. After fixation by a $50 \%$ methanol and 5\% acetic acid solution, the gel was stained with $1 \%$ Coomassie Blue R250 dye. Collagenase activity appeared as clear bands within the stained gel.

\section{Densitometric Estimation of Collagenase}

The intensities of the bands were measured on a Power Macintosh G3 computer (Apple Computer, Cupertino, Calif) with an optical scanner with the public domain National Institutes of Health Image 1.61 software.

\section{Western Blotting of Collagenase}

Immunoblot analysis was carried out as previously described. ${ }^{22,23}$ Proteins in the gel were transferred to nitrocellulose membranes. Before probing, the membrane was blocked in $5 \%$ bovine serum albumin in Tris-buffered saline solution ( $\mathrm{pH}$ 7.6) containing $0.1 \%$ Tween-20 (TBS-T) at $4{ }^{\circ} \mathrm{C}$ overnight. Then the membrane was probed in fresh blocking buffer containing either anti-matrix metalloproteinase 1 (anti-MMP-1), anti-MMP-2, or anti-MMP-9 (Chemicon, Boronia, Victoria, Australia) for 1 hour at room temperature. After extensive washing with TBS-T, a secondary antibody reaction was performed with horseradish peroxidase-conjugated donkey anti-rabbit immunoglobulin at a dilution of 1:5000 in TBS-T. After a final wash, the membrane was treated with Western blotting detection reagents and Hyperfilm-enhanced chemiluminescence reagents (Amersham Pharmacia Biotech UK Limited, Little Chalfont, Buckinghamshire, United Kingdom), and chemiluminescence was detected by means of exposure to enhanced chemiluminescence.

\section{Statistical Analysis}

The value of collagen contents of each cryopreserved cusp was expressed as a percentage of that of each corresponding fresh cusp. NDCs and CDCs were expressed as actual counts. The values of 6 cusps were averaged (means \pm SD). Paired data were compared by using a $t$ test (Microsoft Excel 98; Microsoft Corp, Redmond, Wash).

\section{Results}

Collagen Fiber and Contents in Cryopreserved Cusps

Collagen fibers of the cryopreserved cusp were specifically stained with the Sirius red dye, as shown in Figure 1. Among the cryopreserved cusps, collagen contents themselves were maintained at $102 \% \pm 20.6 \%$ of those of the freshly harvested cusps. There was no significant difference $(P=.56)$ between the collagen contents of the freshly preserved cusps and those of the cryopreserved cusps immediately after the thawing process.

\section{Collagen and Protein Synthesis in Cryopreserved Cusps}

Among cryopreserved cusps, NDCs (ie, one parameter of the protein synthesis) decreased significantly $(P=.0019)$, from $3862 \pm 1180$ counts $/ \mathrm{mg}$ to $1174 \pm 1362$ counts $/ \mathrm{mg}$ (Figure 2). However, among cryopreserved cusps, CDCs (ie, the parameter of the collagen synthesis) were preserved at $831 \pm 762$ counts/mg compared with $1062 \pm 136$ counts of the freshly preserved cusps $(P=.45)$. A curious discrepancy between the collagen synthesis ability and the protein synthesis ability of the cryopreserved cusps was observed immediately after the thawing process.

\section{Collagenase Activity in Cryopreserved Cusps}

Three major gelatinolytic (collagenolytic) bands were found in the gelatin zymography of both groups (Figure 3, A). These gelatinolytic bands were ascertained to be MMP-1 and MMP- 

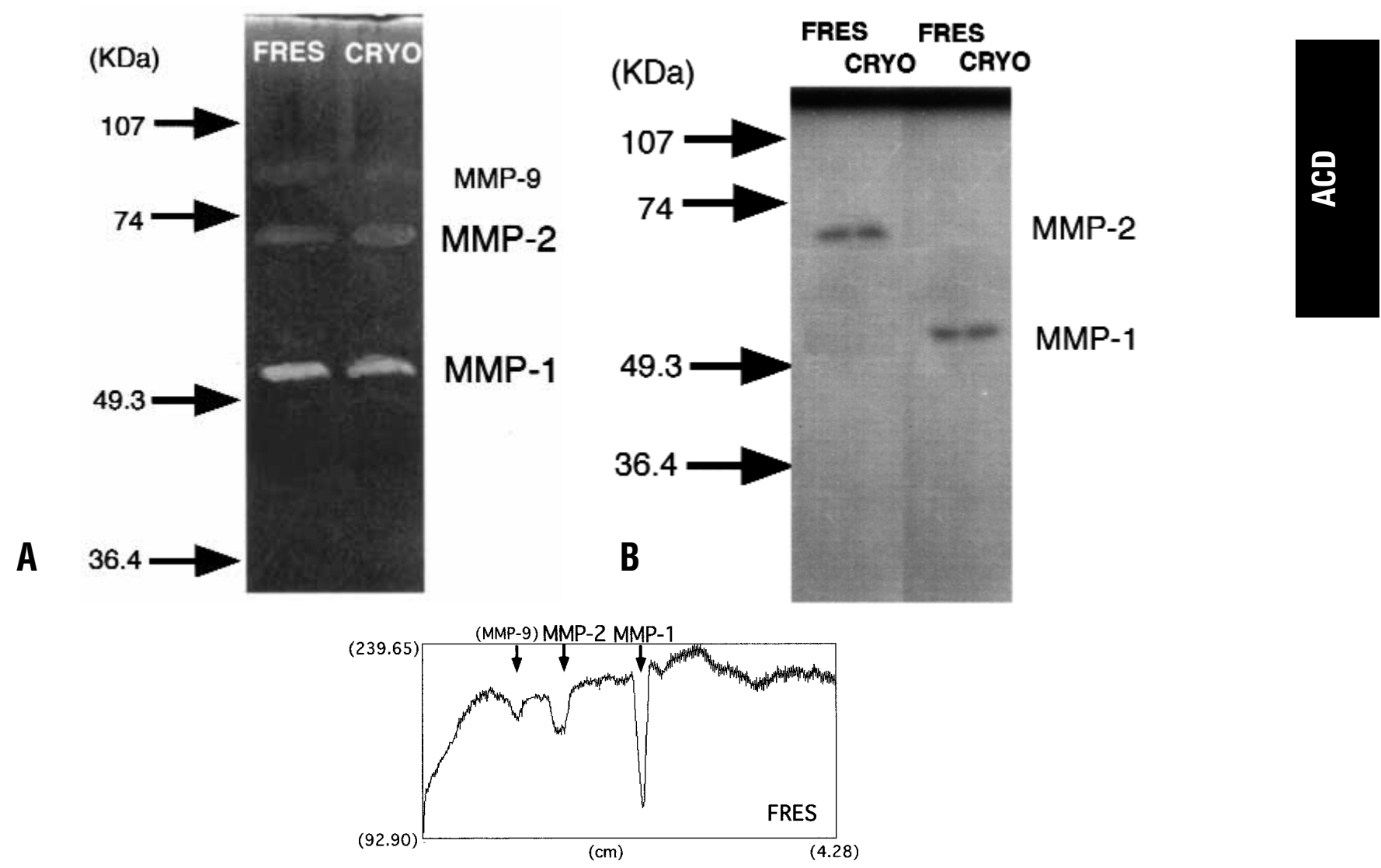

C

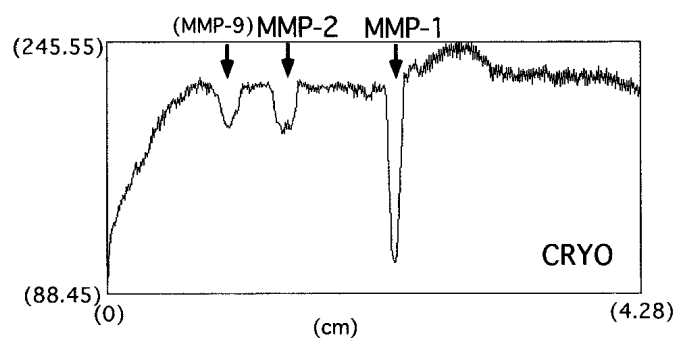

Figure 3. A, Gelatin zymogram of fresh and cryopreserved cusps. There are 3 major gelatinolytic bands. Molecular weights of MMP-1, MMP-2, and MMP-9 are 54, 72, and 92 kd, respectively. B, Western blot analysis of the fresh and cryopreserved cusps. Bands of MMP-1 and MMP-2 are detected. C, Densitometric evaluation of the fresh and cryopreserved cusps. Activity of MMP-1 and MMP-2 in the supernatant of the cryopreserved cusps was observed at the quantitatively same degree as those of the fresh cusps. FRES, Freshly preserved cusps; CRYO, cryopreserved cusps.

2 according to the molecular weight standards and the Western Blot analysis (Figure 3, B). The collagenase activity of the cryopreserved group was observed at the same level as that of the freshly preserved group immediately after the thawing process (Figure 3, C).

\section{Discussion}

The long-term durability of the cryopreserved allograft valves has not yet been fully achieved. Some reports pointed out the deterioration and malfunction of the implanted cryopreserved valves. ${ }^{4-7}$ Mitchell and colleagues ${ }^{8}$ morphologically reported the nonviability and the flattened collagen network of the cryopreserved allograft valves and suggested that their usual degeneration cannot be attributed to immunologic response. ${ }^{15}$ However, these precise mechanisms of the degenerative changes and the allograft valve failure have not yet been clearly revealed.

Durability of the cryopreserved valves seems to be dependent on the fibroblast viability. ${ }^{1-3}$ Lupinetti and associates $^{4,5}$ demonstrated the presence of procollagen and the 
$\alpha_{1}$-(I) procollagen gene expression in aortic allograft valves after implantation for 3 days, which suggested the viability of donor fibroblasts. Fibroblasts have been known to exist within the matrix and participate in the valve remodeling through the collagen metabolism. In our present study the collagen content in the cryopreserved cusps was kept at the same degree as that of the fresh cusps, and the collagen synthesis ability in the cryopreserved cusps was also relatively preserved. However, the protein synthesis ability, including collagen synthesis, in the cryopreserved cusps decreased significantly, although the collagen synthesis ability is preserved, like the data of Lupinetti and associates, and therefore much reduction of protein synthesis ability remains to be discussed.

The MMPs are a family of zinc-dependent enzymes that are able to digest a wide range of extracellular matrix proteins. ${ }^{13}$ The expression of the MMPs from the endothelial cells, the fibroblast cells, and the ischemic myocardium was consecutively revealed. ${ }^{20-23}$ MMP-1, the interstitial collagenase, is mainly produced from the fibroblast and is known to degrade structural type I collagen in the matrix. MMP-2 and MMP-9 are mainly produced from the endothelium and are known to be involved in the degradation of type IV collagen that is a major component of the subendothelial basement membrane. ${ }^{13,24}$

Our previous study demonstrated that the cytosolic and mitochondrial functions of endothelial cells were damaged seriously during the cryopreservation and thawing processes, and those processes may cause a latent cytosolic and mitochondrial injury, even in the fibroblasts. ${ }^{14}$ Despite the anticipated reduced cellular viability, particularly that of endothelial cells, in the cryopreserved cusps, the activity of the MMP-1 and MMP-2 in the supernatant of the cryopreserved cusps was observed at the quantitatively same degree as those of the fresh cusps. These results imply that the cryopreservation and thawing process cause MMP-1 and MMP-2 release from endothelial and fibroblast cells of allograft cusps and activate them before the implantation. There is a possibility that the activated MMP-2 will degrade the basement membrane consisting of type IV collagen and that activated MMP-1 will destroy the cusp matrix. Most cryopreserved valves may have the potential to degrade the matrix.

From those apparently discrepant results, we think that the collagen synthesis ability is preserved, even in the slightly injured fibroblast cells of cryopreserved valves; however, the protein synthesis ability might be extremely reduced because of limited endothelial collaboration ${ }^{25,26}$ and the decrease of the protein production relevant to the intracellular organellar function, which maintains the cell viability. ${ }^{14}$ Furthermore, the collagenolytic activation occurs just before implantation and must be considered. As to those results, the injured fibroblasts are going to be nonviable. Collagen synthesis might be supposed to deteriorate, and the original collagenous skeleton degrades in the near future.

Although it is necessary to elucidate the dynamics of tissue inhibitors of MMPs in the cryopreserved valves, the control of the MMPs' activity in the cryopreserved valves may become more effective to obtain the long-term durability rather than the preservation of collagen synthesis ability. Recently, there were some reports that doxycycline, a derivative of tetracycline, suppresses the development of the elastase-induced abdominal aortic aneurysms through direct MMP-inhibiting activities. ${ }^{27}$ Other MMP inhibitors, marimastat (BB-2516), ${ }^{28}$ batimastat (BB-94), and BE16627B, are also developed as agents for the inhibition of cancer metastasis. These agents might improve the allograft preservation for clinical use.

In conclusion, this study suggests the possibility that the cryopreservation and thawing processes themselves may cause the collagenolytic activation and the latent degradation of collagen synthesis in a cryopreserved valve, which will lead to the destruction of the valve matrix. Further examination for collagen metabolism and modulation of the collagenolytic activity will be necessary to improve the allograft preservation for better clinical use.

\section{References}

1. Niwaya K, Sakaguchi H, Kawachi K, Kitamura S. Effect of warm ischemia and cryopreservation on cell viability of human allograft valves. Ann Thorac Surg. 1995;60:S114-7.

2. Lu JH, Chiu YT, Sung HW, Hwang B, Chong CK, Chen SP, et al. $\mathrm{XTT}$-colorimetric assay as a marker viability in cryoprocessed cardiac valve. J Mol Cell Cardiol. 1997;29:1189-94.

3. Lester WM, Damji AA, Tanaka M, Gedeon I. Bovine mitral valve organ culture: role of interstitial cells in repair of valvular injury. $\mathrm{J} \mathrm{Mol}$ Cell Cardiol. 1992;24:43-53.

4. Lupinetti FM, Kneebone JM, Rekhter MD, Brockbank KGM, Gordon D. Procollagen production in fresh and cryopreserved aortic valve grafts. J Thorac Cardiovasc Surg. 1997;113:102-7.

5. Song YC, Yao LY, Kneebone JM, Lupinetti FM. Effect of cryopreservation and histocompatibility on type I procollagen gene expression in aortic valve grafts. J Thorac Cardiovasc Surg. 1997;114:421-7.

6. McGregor CGA, Bradley JF, McGee JO, Wheatley DJ. Tissue culture, protein and collagen synthesis in antibiotic sterilized canine heart valves. Cardiovasc Res. 1976;10:389-93.

7. Brockbank KG. Cell viability in fresh, refrigerated, and cryopreserved human heart valve leaflets. Ann Thorac Surg. 1990;49:848-9.

8. Mitchell RN, Jonas RA, Schoen FJ. Structure-function correlations in cryopreserved allograft cardiac valves. Ann Thorac Surg. 1995;60:S108-13.

9. Salim KA, DiSessa TG, Alpert BS, Arheart KL, Novick WM, Watson DC. The fate of homograft conduits in children with congenital heart disease: an angiographic study. Ann Thorac Surg. 1995;59:67-73.

10. Mitchell RN, Jonas RA, Schoen FJ. Pathology of explanted cryopreserved allograft heart valves: comparison with aortic valves from orthotopic heart transplants. J Thorac Cardiovasc Surg. 1998;115:118-27.

11. Baskett RJ, Ross DB, Nanton MA, Murphy DA. Factors in the early failure of cryopreserved homograft pulmonary valves in children: preserved immunogenecity? J Thorac Cardiovasc Surg. 1996;112:1170-9.

12. Wassenaar C, Wijsmuller EG, Van Herwerden LA, Aghai Z, Van Tricht CLJ, Bos E. Cracks in cryopreserved aortic allografts and rapid thawing. Ann Thorac Surg. 1995;60:S165-7. 
13. Woessner JF Jr. Matrix metalloproteinases and their inhibitors in connective tissue remodeling. FASEB J. 1991;5:2145-54.

14. Tominaga T, Kitagawa T, Masuda Y, Hori T, Kano M, Yasuta O. Viability of cryopreserved semilunar valves: an evaluation of cytosolic and mitochondorial activities. Ann Thorac Surg. 2000;70:792-5.

15. Coats WD, Whittaker P, Cheung TC, Currier JW, Han B, Faxon DP. Collagen content is significantly lower in restenotic versus nonstenotic vessels after balloon angioplasty in the atherosclerotic rabbit model. Circulation. 1997;95:1293-300.

16. Volders PGA, Willems IEM, Cleutjens JPM, Arends JW, Havenith MG, Daemen JAP. Interstitial collagen is increased in the non-infarcted human myocardium after myocardial infarction. $J$ Mol Cell Cardiol. 1993;25:1317-23.

17. Henney AM, Parker DJ, Davies MJ. Collagen biosynthesis in normal and abnormal human heart valves. Cardiovasc Res. 1982;16:624-30.

18. Waard JWD, de Man BM, Wobbes T, van der Linden, Hendriks T. Inhibition of fibroblast collagen synthesis and proliferation by levamisole and 5-fluorouracil. Eur J Cancer. 1998;1:162-7.

19. Gogly B, Groult N, Hornebeck W, Godeau G, Pellat B. Collagen zymography as a sensitive and specific technique for the determination of subpicogram levels of interstitial collagenase. Anal Biochem. 1998;255:211-6.

20. Danielsen CC, Wiggers H, Andersen HR. Increased amounts of collagenase and gelatinase in porcine myocardium following ischemia and reperfusion. J Mol Cell Cardiol. 1998;30:1431-42.
21. Cleutjens JP, Kandala JC, Guarda E, Guntaka RV, Weber KT. Regulation of collagen degradation in the rat myocardium after infarction. J Mol Cell Cardiol. 1995;27:1281-92.

22. Tyagi SC, Kumar S, Katwa L. Differential regulation of extracellular matrix metalloproteinase and tissue inhibitor by heparin and cholesterol in fibroblast cells. J Mol Cell Cardiol. 1997;29:391-404.

23. Belkhiri A, Richards C, Whaley M, McQueen SA, Orr FW. Increased expression of activated matrix metalloproteinase- 2 by human endothelial cells after sublethal $\mathrm{H}_{2} \mathrm{O}_{2}$ exposure. Lab Invest. 1997;77:533-9.

24. Simionescu A, Simionescu D, Deac R. Biochemical pathways of tissue degeneration in bioprosthetic cardiac valves. ASAIO J. 1996;43: M561-7.

25. Villanueva AG, Farber HW, Rounds S, Goldstein RH. Stimulation of fibroblast collagen and total protein formation by an endothelial cell-derived factor. Cir Res. 191;69:134-4.

26. Guarda E, Myers PR, Brilla CG, Tyagi SC, Weber KT. Endothelial cell induced modulation of cardiac fibroblast collagen metabolism. Cardiovasc Res. 1993;27:1004-8.

27. Curci JA, Petrinec D, Liao S, Lorne M, Golub DMD, Thompson RW. Pharmacologic suppression of experimental abdominal aortic aneurysms: a comparison of doxycycline and four chemically modified tetracycline. J Vasc Surg. 1998;28:1082-93.

28. Portes KE, Loftus IM, Peterson M, Bell PRF, London NJM, Thompson MM. Marimastat inhibits neoinitimal thickening in a model of human vein graft stenosis. Br J Surg. 1998;85:1373-7.

\section{Authoritative}

The Journal of Thoracic and Cardiovascular Surgery is the most frequently cited thoracic/cardiovascular surgery journal in the Science Citation Index. An article in JTCVS is sited on average almost twice as often as those in the closest cardiothoracic journal. 